\title{
TRPC6 in simulated microgravity of intervertebral disc cells
}

\author{
Alfredo Franco-Obregón ${ }^{1,2} \cdot$ Elena Cambria ${ }^{3} \cdot$ Helen Greutert ${ }^{3} \cdot$ Timon Wernas $^{4} \cdot$ Wolfgang Hitzl $^{5,6} \cdot$ Marcel Egli $^{4}$. \\ Miho Sekiguchi $^{7} \cdot$ Norbert Boos $^{8}$. Oliver Hausmann ${ }^{9} \cdot$ Stephen J. Ferguson $^{3} \cdot$ Hiroshi Kobayashi $^{3,7}$. \\ Karin Wuertz-Kozak ${ }^{3,10,11,12}$
}

Received: 19 November 2017 / Accepted: 25 June 2018 / Published online: 2 July 2018

(c) The Author(s) 2018

\begin{abstract}
Purpose Prolonged bed rest and microgravity in space cause intervertebral disc (IVD) degeneration. However, the underlying molecular mechanisms are not completely understood. Transient receptor potential canonical (TRPC) channels are implicated in mechanosensing of several tissues, but are poorly explored in IVDs.

Methods Primary human IVD cells from surgical biopsies composed of both annulus fibrosus and nucleus pulposus (passage 1-2) were exposed to simulated microgravity and to the TRPC channel inhibitor SKF-96365 (SKF) for up to 5 days. Proliferative capacity, cell cycle distribution, senescence and TRPC channel expression were analyzed.

Results Both simulated microgravity and TRPC channel antagonism reduced the proliferative capacity of IVD cells and induced senescence. While significant changes in cell cycle distributions (reduction in G1 and accumulation in G2/M) were observed upon SKF treatment, the effect was small upon 3 days of simulated microgravity. Finally, downregulation of TRPC6 was shown under simulated microgravity.

Conclusions Simulated microgravity and TRPC channel inhibition both led to reduced proliferation and increased senescence. Furthermore, simulated microgravity reduced TRPC6 expression. IVD cell senescence and mechanotransduction may hence potentially be regulated by TRPC6 expression. This study thus reveals promising targets for future studies.
\end{abstract}

Graphical abstract These slides can be retrieved under Electronic Supplementary Material.

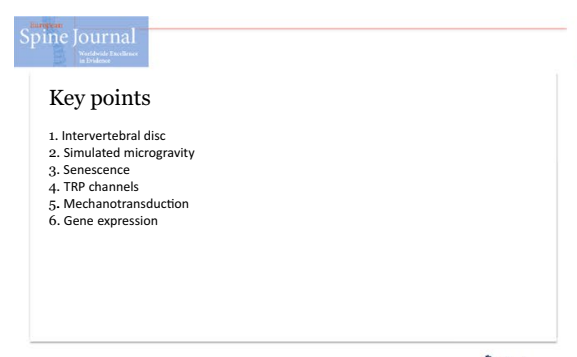

을 Springer

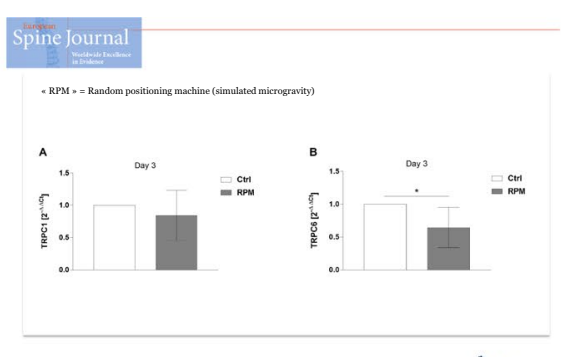

Q Springer

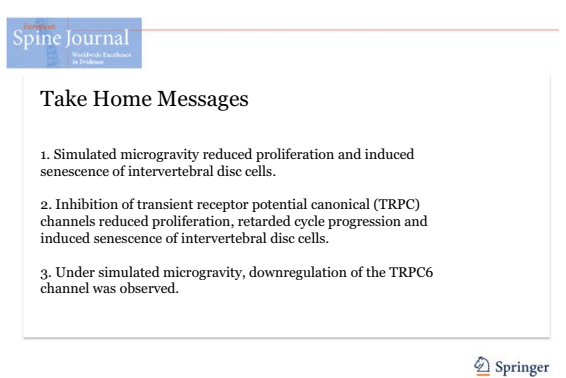

Alfredo Franco-Obregón and Elena Cambria have contributed equally to this work.

Hiroshi Kobayashi and Karin Wuertz-Kozak have contributed equally to this work.

Electronic supplementary material The online version of this article (https://doi.org/10.1007/s00586-018-5688-8) contains supplementary material, which is available to authorized users.

Extended author information available on the last page of the article 
Keywords Intervertebral disc $\cdot$ Simulated microgravity $\cdot$ Senescence $\cdot$ TRP channels $\cdot$ Mechanotransduction $\cdot$ Gene expression

\section{Introduction}

Intervertebral discs (IVDs) show signs of degeneration as early as the second decade of life [1]. As normal physiological ageing and pathological degeneration recruit similar signalling cascades, pathological IVD degeneration can be described as accelerated tissue ageing, contributed to by multimodal stress-induced changes with ultimate tissue failure [2]. Although genetics plays an essential role in the onset of ageing and the progression of degeneration [3], mechanical loading and damage, particularly of the lumbar spine, have been identified as contributing factors [4]. Whereas physiological levels of mechanical stress support the metabolic balance of the IVD [5], hyper-physiological mechanical stresses or mechanical unloading biases the IVD towards catabolism, inflammation and reduced viability, hence promoting degeneration [6]. Mechanical unloading, occurring, e.g. during prolonged bed rest, causes long-lasting changes in IVDs [7, 8]. In fact, the changes in IVD morphology measured by magnetic resonance imaging after 21 days of bed rest in 7 healthy subjects persisted after 5 months [7]. The recovery of the IVDs was still incomplete 2 years after 60 days of bed rest [8]. Moreover, astronauts, who are exposed to microgravity during space flights, exhibit spinal lengthening [9], low back pain [10, 11] and an elevated risk of IVD herniation [12]. In vitro experiments [13] and animal studies conducted during space flight $[14,15]$ have shown degenerative biomechanical or biochemical effects of microgravity. To study microgravity on Earth, random positioning machines (RPMs) are commonly used [16]. Signs of IVD degeneration were observed in mice discs cultured in a rotary wall vessel bioreactor [17], although this was not the case with rat IVDs [18].

During degeneration, IVD cells acquire numerous pathobiological features, including increased levels of cellular senescence $[19,20]$. Affected cells possess a socalled senescence-associated secretory phenotype (SASP), characterized by proliferative dysfunction, unresponsiveness to mitogenic stimulation (and hence hampered cell cycle progression), as well as catabolic and inflammatory behaviour [20]. The molecular mechanisms leading to IVD degeneration and ageing are not yet completely understood. However, high levels of free calcium in the cartilaginous endplates are associated with IVD degeneration [21]. Furthermore, free calcium seems to contribute to IVD degeneration through the calcium-sensing receptor (CaSR) [22]. Recently, the expression of transient receptor potential (TRP) channels, a superfamily of ion channel with relevance in calcium regulation [23], has been demonstrated in the IVD [24-26]. The members of the canonical family (TRPC) are especially interesting. A direct correlation between TRPC6 expression and the degree of IVD degeneration has been recently shown [25], highlighting TRPC6 as a candidate for further studies on IVD pathobiology. Aside from TRPC6, the isoform TRPC1 may also be of specific relevance. TRPC1 and TRPC6 are both known to affect cell cycle progression in various cell types [27-29], and TRPC6 was shown to modulate cellular senescence [30]. Therefore, their modulation and (dys-)regulation may play a crucial role in IVD health, but also degeneration. Importantly, TRPC1 and TRPC6 have both been described as mechanosensitive [26]. TRP channels are therefore interesting candidates when aiming to link IVD mechanobiology with IVD ageing and degeneration. Interestingly, simulated microgravity was shown to depress TRPC1 expression associated with an accumulation of cells into $\mathrm{G} 2 / \mathrm{M}$, effectively stalling proliferation of mouse myoblasts [28, 31].

The aim of this study was to investigate the effects of simulated microgravity and TRPC channel pharmacological inhibition on human IVD cell proliferation, cell cycle progression and senescence (as key features of IVD degeneration).

\section{Materials and methods}

\section{Cell isolation and culture}

Primary cells were isolated from human IVD biopsies from patients undergoing spinal surgery (approved by the ethical committees in Zurich and Lucerne, Switzerland, and after informed consent), as previously described [32]. For patient demographics, see Table 1. Biopsies were composed of both annulus fibrosus and nucleus pulposus (with different ratio), as it is difficult to distinguish these tissues in degenerated samples. The $n$ number in each experiment (between 4 and 6) represents the number of donors used per experimental condition.

Cells were cultured in DMEM/F-12 (Gibco, 31330-038) with 10\% FCS (Sigma-Aldrich, F7524) and 1\% Anti-Anti (=50 units $/ \mathrm{mL}$ penicillin, $50 \mu \mathrm{g} / \mathrm{mL}$ streptomycin and $125 \mathrm{ng} / \mathrm{mL}$ ampicillin) (Gibco, 15240-062) at $37^{\circ} \mathrm{C}$ and 5\% $\mathrm{CO}_{2}$ up to passage 1-2. For the experimental phase, cells were cultured in reduced-serum DMEM/F12 (5\% FCS) without antibiotics to avoid any possible interaction of aminoglycoside antibiotics with TRP channel activity [28]. 
Table 1 Patient demographics

\begin{tabular}{llllll}
\hline $\begin{array}{l}\text { Patient } \\
\text { number }\end{array}$ & Patient age & Sex & Disc level & Type of disease & $\begin{array}{l}\text { Pfir- } \\
\text { mann } \\
\text { grade }\end{array}$ \\
\hline 1 & 62 & F & L4/5 & Spondylolisthesis & V \\
2 & 53 & M & L5/S1 & Herniation & IV \\
3 & 71 & F & L4/5 & DDD & II \\
4 & 42 & F & L4/5 & Herniation & IV \\
5 & uk & uk & uk & uk & uk \\
6 & 46 & M & L5/S1 & DDD & V \\
7 & 43 & F & L4/5 & Herniation & IV \\
8 & uk & uk & uk & uk & uk \\
9 & 41 & F & L5/S1 & Herniation & IV \\
10 & 47 & F & L4/L5 & Herniation & III \\
11 & 56 & F & L3/4 & Herniation & IV \\
12 & 57 & M & L5/S1 & DDD & IV \\
13 & 68 & M & L4/5 & Herniation & III \\
14 & uk & uk & uk & uk & uk \\
15 & 40 & F & C6/7 & Herniation & III \\
16 & 44 & M & L4/5 & Herniation & IV \\
\hline
\end{tabular}

$F=$ female $M=$ male; $L 4 / 5=$ lumbar $4-5 ; L 5 / S 1=$ lumbar 5 -sacral 1 ; $C 6 / 7=$ cervical $6-7 ; D D D=$ degenerative disc disease $u k=$ unknown

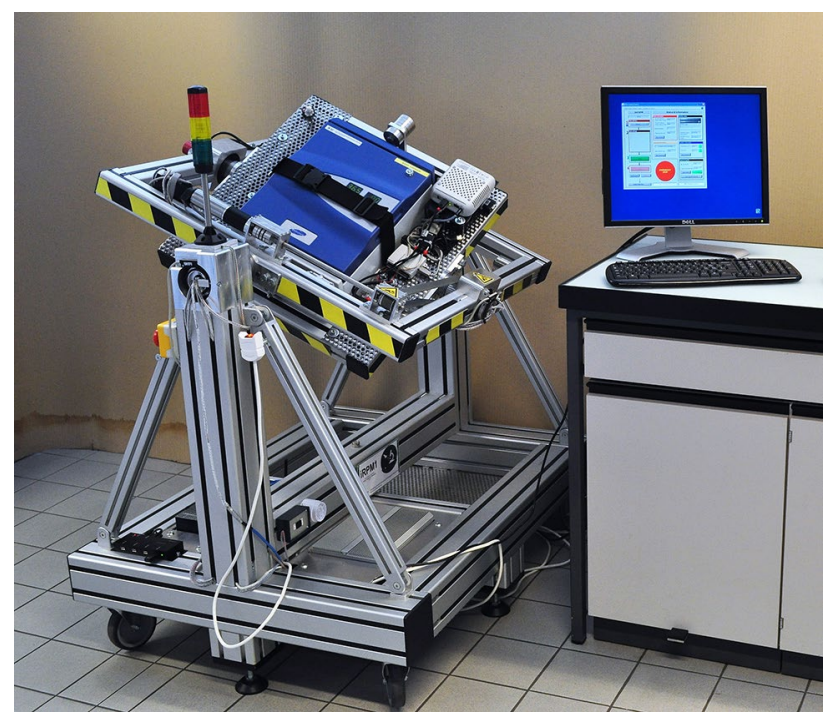

Fig. 1 Photograph of the random positioning machine (RPM) used in this study. The samples were mounted in the integrated miniaturized $\mathrm{CO}_{2}$ incubator in the inner of the two rotating gimbal-mounted frames that are independently moved by motors

\section{Cellular treatments}

\section{Simulated microgravity}

To expose cells to simulated microgravity, a previously described RPM was used (Fig. 1) [28]. The RPM consists of two gimbal-mounted frames independently moved by motors. Samples are placed at the centre of the frames, where the generated motion pattern is designed to equally distribute the gravity vector spatially and temporally (the gravity mathematically averages zero) [33]. Because the constant reorientation of the gravity vector prevents biological systems to adjust to this force, their response is similar to the one achieved upon real microgravity exposure [16].

In our experiments, the rotation speed of the frames was set to $60^{\circ}$ per second. IVD cells $(n=4-5$, seeded at 6000 cells $/ \mathrm{cm}^{2}$ in T25 flasks $(150,000$ cells per flask)) were cultured for $24 \mathrm{~h}$ prior to simulated microgravity. Flasks were completely filled with culture medium to avoid air bubbles and closed airtight with a filter-less cap [28]. Flasks were mounted onto the RPM (integrated miniaturized $\mathrm{CO}_{2}$ incubator), whereas corresponding control samples $(1 \mathrm{~g})$ were cultured in the same conditions and simultaneously kept in a standard $\mathrm{CO}_{2}$ incubator [28]. Treated cells were analyzed for proliferation (up to 5 days of treatment), cell cycle progression ( $24 \mathrm{~h}$ of treatment), cellular senescence $(72 \mathrm{~h}$ of treatment) and TRP channel expression ( $72 \mathrm{~h}$ of treatment) and compared to untreated controls.

\section{Pharmacological TRPC channel inhibition}

Twenty-four hours before pharmacological TRPC inhibition with the broad TRPC antagonist SKF-96365 [34] (SigmaAldrich, S7809), IVD cells were seeded at a density of $\sim 8000$ cells $/ \mathrm{cm}^{2}$ in either 24-well plates for subsequent analysis of proliferation ( $n=6,15,000$ cells per well), $25 \mathrm{~cm}^{2}$ flasks for cell cycle analysis ( $n=6,200,000$ cells per flask), or 12-well plates for senescence analysis ( $n=530,000$ cells per well). For cell cycle analysis, cells were exposed to high doses of SKF-96365 $(20 \mu \mathrm{M})$ for $48 \mathrm{~h}$, whereas proliferation and senescence experiments were conducted for up to 5 days at lower concentrations ( 1.7 and $2.5 \mu \mathrm{M})$ to avoid cell death or complete growth arrest. Treated cells were analyzed as described below and compared to untreated controls.

\section{Cell analysis}

\section{Cell proliferation}

Manual counting of trypsinized cells was conducted to identify the effects of simulated microgravity and pharmacological TRP inhibition on cell proliferation. Proliferation was analyzed over 5 days (day $0=$ seeding cell number, 1,3 and 5 ) by counting each replicate twice using a hemocytometer.

\section{Cell cycle}

Cell cycle progression was analyzed by flow cytometry analysis as previously described [28]. Cells were fixed in 
$70 \%$ ice-cold EtOH, stored at $-20{ }^{\circ} \mathrm{C}$ overnight and then stained with PI/RNase staining buffer (BD Pharmingen, 550825). Cells were analyzed with a FACSCalibur system (BD Biosciences), outfitted with a FL1 channel for PI staining. Appropriate settings for forward- and side-scatter gates were applied to examine $10^{\prime} 000$ events/sample. The cell cycle profile was quantified with FlowJo flow cytometry analysis software (TreeStar Inc.), applying the Watson model to fit the histograms of single-gated cells.

\section{Senescence}

The level of cellular senescence was assessed by SA- $\beta$ galactosidase staining. Cells were washed twice with PBS, fixed with 3\% paraformaldehyde in PBS (pH 7.4), washed twice with PBS and incubated overnight at $37{ }^{\circ} \mathrm{C}$ with X-gal chromogenic substrate $(1 \mathrm{mg} / \mathrm{ml})$ at $\mathrm{pH} 6.0$ [35]. After washing and dehydration with graded ethanol (75-95-99.9\%, 1 min each), six images per sample were taken under brightfield illumination $(10 \times)$. The percentage of senescent cells was determined by manually counting cells with ImageJ.

\section{Gene expression}

Gene expression analysis was conducted using a previously described protocol [36]. Briefly, RNA was extracted with TRIzol/chloroform (ThermoScientific, 15596018), the quality and quantity of RNA was determined with the NanodropLite (ThermoScientific) and $1 \mu \mathrm{g}$ of RNA was reverse-transcribed into cDNA in a $30 \mu \mathrm{l}$ volume using the High-Capacity cDNA Reverse Transcription Kit (Applied Biosystems, 4374966). For each qPCR reaction, 150 ng cDNA was mixed with TaqMan primers (TRPC1: Hs00608195_m1; TRPC6: Hs00989190_m1; TBP: Hs00427620_ml), TaqMan Fast Universal PCR Master Mix (2X) (Applied Biosystems, 4352042) and RNAse-free water to a total volume of $10 \mu \mathrm{l}$ and gene expression was measured with the CFX96 Touch ${ }^{\mathrm{TM}}$ Detection System (Bio-Rad). TATA-binding protein (TBP) was used as a housekeeping gene. Results are shown as $2^{-\Delta \Delta \mathrm{Ct}}$ values (i.e. relative to TBP and relative to the untreated control).

\section{Statistical analysis}

Data were analyzed for consistency, outliers and for normality. We used normal probability plots for visual inspection of data and Kolmogorov-Smirnov tests to test for normality. Because each donor was measured in the control as well as in the experimental group, samples were dependent (clustered). Data were not normally distributed in any subgroup, and to consider both circumstances, a generalized estimation equation model (GEE) was applied. In detail, we applied a full factorial model with a main, time and interaction effects and used the robust Huber-White sandwich estimator for the covariance matrix (unstructured approach). The lognormal distribution was used to model the underlying distribution. Least significance differences were computed for pairwise comparisons of means. Results are given in terms of means, standard deviations and 95\% confidence intervals for means. A significance level of $5 \%$ was used. All tests were two-sided. All analyses were done by using STATISTICA 13 (Hill, T. \& Lewicki, P. Statistics: Methods and Applications. StatSoft, Tulsa, OK) and PASW 24 (IBM SPSS Statistics for Windows, Version 24.0., Armonk, NY).

\section{Results}

\section{Simulated microgravity and TRPC channel inhibition reduce cell proliferation}

Exposing IVD cells $(n=5)$ to simulated microgravity significantly reduced proliferation at days 3 (189 573 cells \pm 54 620) and 5 (337 325 cells \pm 184 026) compared to cells maintained at $1 \mathrm{~g}$ (day 3: 365600 cells \pm 21637 , $p<0.0001$; day 5: 620463 cells $\pm 394720, p=0.0041)$ (Fig. 2a). Similarly, IVD cell proliferation rate $(n=6)$ was slowed at day 3 and day 5 by SKF-96365 (1.7 and $2.5 \mu \mathrm{M})$, a non-selective TRPC channel antagonist (Fig. 2b) [34]. Statistical significance was reached both when comparing each SKF concentration to the control group $(p<0.0001$ for both concentration at both day 3 and 5) and when comparing the $1.7 \mu \mathrm{M}$ to the $2.5 \mu \mathrm{M}$ group $(p=0.0007$ and $p=0.002$ for day 3 and 5 , respectively), thus proving dose-dependency.

\section{Simulated microgravity and TRPC channel inhibition affect cell cycle}

Although $24 \mathrm{~h}$ of simulated microgravity slightly reduced the mean percentage of cells in the G1 phase of the cell cycle from $64.6 \% \pm 8.5$ in the controls to $59.0 \% \pm 6.1$ and caused an accumulation within the $\mathrm{G} 2 / \mathrm{M}$ phase from $11.6 \pm 1.9$ to $15.2 \% \pm 3.6$, these differences were not significant $(p=0.062$ and $p=0.076$, respectively) (Fig. 3a). However, short-term pharmacological blocking of TRPC-mediated calcium entry with SKF-96365 (20 $\mu \mathrm{M}, 48 \mathrm{~h})$ resulted in a significant accumulation of IVD cells within the G2/M phase, concomitant with a reduction of cells within the G1 phase $(p<0.0001$ for both phases) (Fig. 3b). Specifically, G2/M accumulation increased from $11.4 \% \pm 6.0$ (untreated control) to $30.3 \% \pm 8.5$, and G1 distribution decreased from $79.7 \% \pm 8.5$ to $56.7 \% \pm 11.9$. 


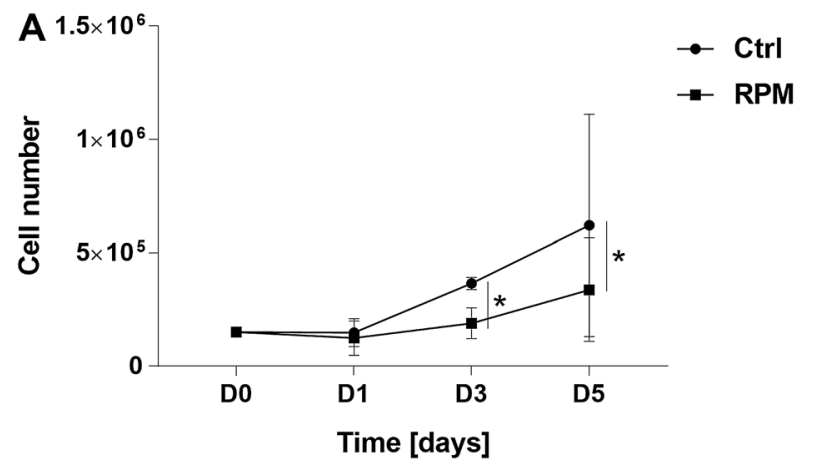

Fig. 2 Effects of simulated microgravity and TRPC channel inhibition on proliferation. a Proliferation (total cell number) of human IVD cells at terrestrial gravity (Ctrl) or exposed to simulated microgravity (RPM) up to 5 days $(n=5)$. b Proliferation (total cell number)

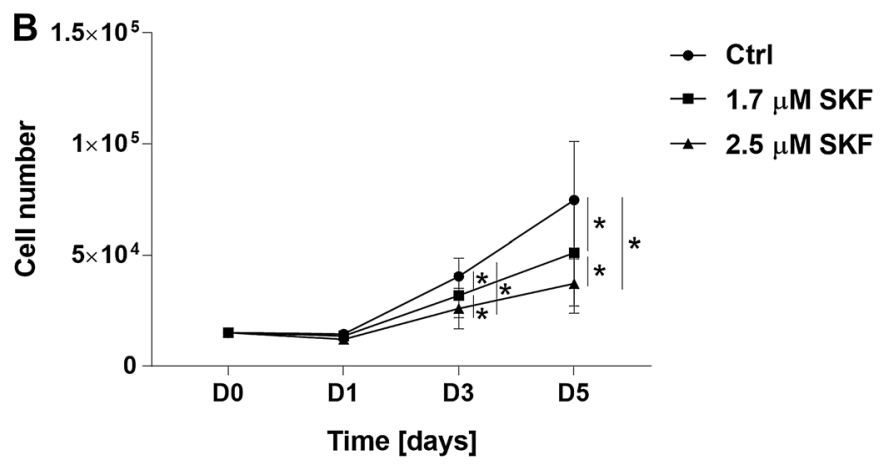

of human IVD cells with or without TRPC channel inhibition with 1.7 or $2.5 \mu \mathrm{M}$ SKF-96365 for up to 5 days $(n=6)$. Data are shown as mean with $95 \%$ confidence interval, ${ }^{*} p<0.05$

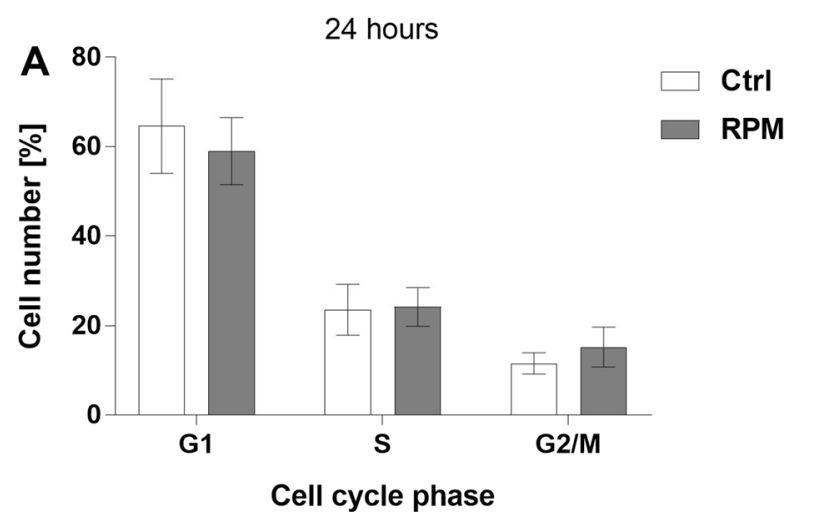

Fig. 3 Effects of simulated microgravity and TRPC channel inhibition on cell cycle. a Cell cycle distribution (\% of cells in each phase) of human IVD cells at $1 \mathrm{~g}(\mathrm{Ctrl})$ or exposed to simulated microgravity (RPM) for $24 \mathrm{~h}(n=5)$. b Cell cycle distribution (\% of cells in each

\section{Simulated microgravity and TRPC channel inhibition increase cellular senescence}

We found that exposing IVD cells to simulated microgravity for 3 days increased senescence (positive SA- $\beta$ galactosidase staining) from $40.0 \% \pm 3.6$ (control group) to $50.0 \% \pm 6.9(p<0.0001)$ (Fig. $4 \mathrm{a})$. Similarly, SKF96365 treatment also augmented the percentage of SA- $\beta$ galactosidase-positive cells relative to untreated controls (Fig. 4b). A significant difference was already observed between the $2.5 \mu \mathrm{M}$ SKF group and controls at day 1 $(p<0.0001)$, which was maintained at both days 3 and 5 ( $p=0.012$ and $p<0.0001$, respectively). At these later time points, statistical significance was also reached for the $1.7 \mu$ M SKF group ( $p=0.0018$ and $p<0.0001)$ (Fig. 4b).

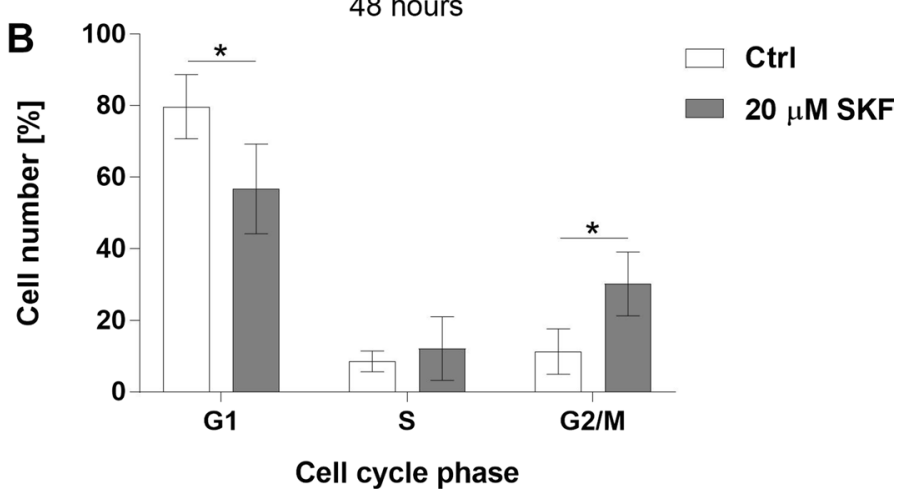

phase) of human IVD cells with or without TRPC channel inhibition with $20 \mu \mathrm{M}$ SKF-96365 for $48 \mathrm{~h}(n=6)$. Data are shown as mean with $95 \%$ confidence interval, $* p<0.05$

\section{Simulated microgravity downregulates TRPC6 expression}

Motivated by the fact that TRPC channel inhibition had similar effects on proliferation, cell cycle progression and senescence to simulated microgravity, we analyzed the gene expression of the TRPC channel isoforms TRPC1 and TRPC6 under simulated microgravity. While TRPC1 mRNA levels were not affected $(p=0.14)$ (Fig. 5a), TRPC6 expression was significantly reduced (mean $2^{-\Delta \Delta \mathrm{Ct}}$ value $=0.64 \pm 0.19, p<0.0001)($ Fig. $5 b)$. 

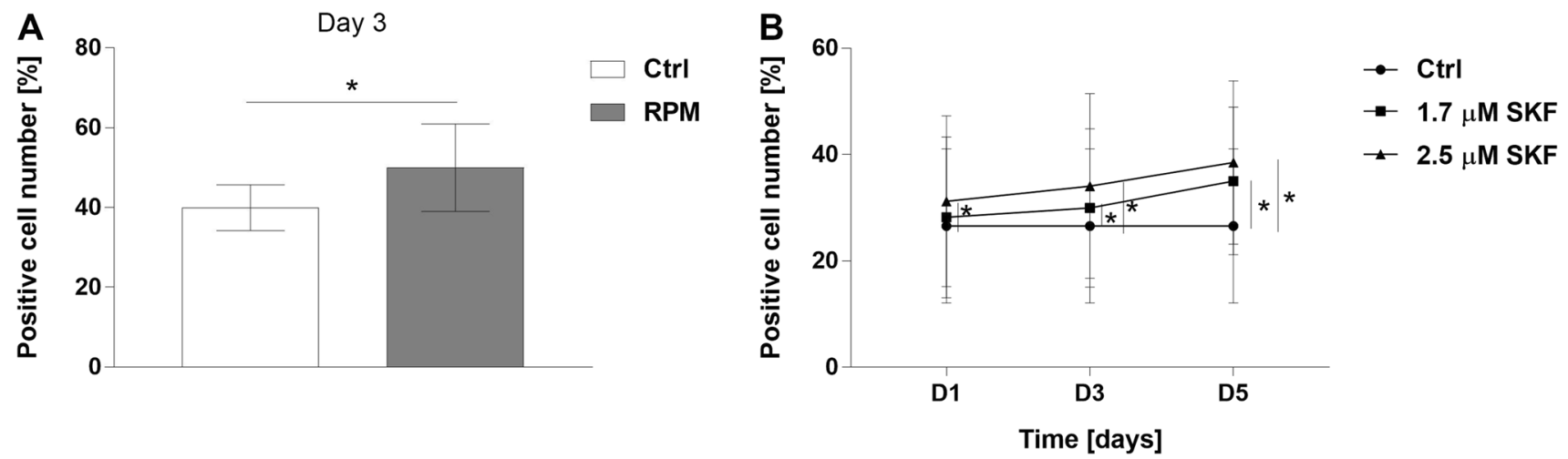

Fig. 4 Effects of simulated microgravity and TRPC channel inhibition on senescence. a Percentage of SA- $\beta$-galactosidase-positive human IVD cells at $1 \mathrm{~g}(\mathrm{Ctrl})$ or exposed to simulated microgravity (RPM) for 3 days $(n=4)$ b Percentage of SA- $\beta$-galactosidase-positive

human IVD cells with or without TRPC channel inhibition with 1.7 or $2.5 \mu \mathrm{M}$ SKF-96365 for up to 5 days $(n=5)$. Data are shown as mean with $95 \%$ confidence interval, ${ }^{*} p<0.05$
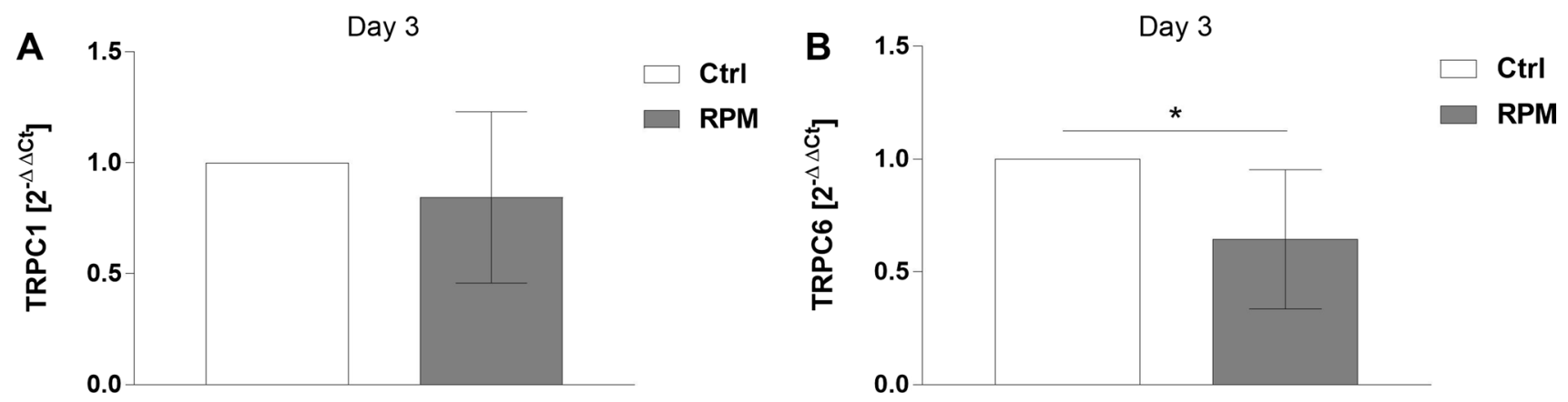

Fig. 5 Gene expression of TRPC1 and TRPC6 under simulated microgravity. a Relative gene expression of TRPC1 and b TPRC6 in human IVD cells at $1 \mathrm{~g}(\mathrm{Ctrl})$ or exposed to simulated micrograv-

ity (RPM) for 3 days $(n=4)$. Results are shown as $2^{-\Delta \Delta \mathrm{Ct}}$ values (i.e. relative to TBP and relative to the untreated control) $(n=4)$. Data are shown as mean with $95 \%$ confidence interval, ${ }^{*} p<0.05$

\section{Discussion}

In this study, we found that (1) simulated microgravity and pharmacological antagonism of TRPC channels reduced cell proliferation, retarded cell cycle progression and induced cellular senescence, and that (2) simulated microgravity concomitantly inhibited TRPC6 expression (while not affecting TRPC1 expression). TRPC6 may hence potentially play a role in mediating the effects on proliferation and cell cycle distribution that were observed upon simulated microgravity. Further studies including modulation of TRPC6 (with, e.g. activation with CRISPRa or knockout with CRISPRi [37]) are needed to reveal the possible involvement of TRPC6 in IVD mechanotransduction.

Mechanical unloading, as observed in astronauts, para-/ tetraplegic patients, bed rest studies [7, 8] or animals undergoing hindquarter suspension, negatively affects IVD metabolism and matrix composition. Here, we simulated microgravity by using an RPM [28] and similarly

observed detrimental, degeneration-associated changes. These changes are likely due to the integrated signalling network that couples mechanosensitive receptors and pathways to gene and transcription modulation [38], and may furthermore be associated with structural adjustments on the cell level (e.g. actin cytoskeleton reorganization) [39].

Although constituting a well-accepted method to simulate microgravity, the use of an RPM with its constant reorientation of the samples induces additional forces (e.g. shear stresses) that may create artefacts. These forces present in the culture flasks on the RPM and their effects on the cultured cells were recently thoroughly studied by numerical analysis [40]. Parameters such as rotational velocity of the RPM play a role in the appearance of shear stress [40]. Therefore, additional stressors and artefacts can be prevented by taking the necessary measures for an accurate operation of the RPM [40]. IVD cell culture in flasks on the RPM does not recapitulate the complex three-dimensional disc matrix environment. However, signs of degeneration were similarly observed in whole mouse discs cultured under microgravity 
in a rotating wall vessel bioreactor [17]. Compared to studies in the entire human (astronauts and bed rest patients), the RPM represents a simplified in vitro model system, which is nevertheless useful to uncover the underlying molecular mechanisms related to IVD degeneration.

In agreement with our results obtained with human IVD cells, murine myoblasts exposed to simulated microgravity or SKF-96365 exhibited reduced proliferation and cell cycle arrest within the G2/M phase [28, 31]. This reflects the fact that proliferative capacity may concurrently correlate with mechanosensitivity and TRPC function [31]. However, myoblasts seem to rely on modulation of TRPC1 rather than TRPC6, indicating that the exact role of these TRP channels appears to be tissue and/or species dependent. To confirm the specific relevance of TRPC6 for IVD mechanosensing and mechanotransduction, future experiments should not only apply SKF-96365 [34, 41] (which may potentially also affect voltage-dependent calcium channels [42]), but should also target TRPC6 in a more specific manner.

Apart from analyzing cell proliferation and cell cycle progression, we also measured changes in cellular senescence (as assessed by SA- $\beta$ galactosidase staining), a hallmark of IVD degeneration [43, 44]. TRPC channel inhibition and simulated microgravity both increased cellular senescence in IVD cells. However, variability in the basal levels of senescence (and proliferation capacity) between donors was present, as these differed with respect to age, pathology, degeneration grade and mixture of NP and AF tissue. Senescence in vivo is not only associated with the degree of disc degeneration [45], but also varies between NP and AF [20]. Furthermore, pro-inflammatory cytokines may trigger cell senescence [45], and these may not only be secreted by resident IVD cells, but also by invading immune cells found predominantly in IVD herniation samples [46]. Despite the differences in basal levels of senescence and proliferation capacity stemming from disparities in patient characteristics, we were able to show that microgravity and TRPC channel inhibition both increased cell senescence and decreased cell proliferation. The subsequent gene expression analysis of the TRPC channel isoforms TRPC1 and TRPC6 revealed that TRPC6 was downregulated under microgravity (while TRPC1 expression was not affected). Therefore, TRPC6 could potentially be of importance in the progression of IVD degeneration linked to cell senescence, but further studies are needed. In fact, the role of TRP channels in modulating senescence is also known for other cell types, such as endothelial cells (TRPC5) [47], pancreatic adenocarcinoma cells (TRPM7, TRPM8) $[48,49]$ and lung fibroblasts (TRPC6) [30].

Mechanistic studies modulating TRPC6 expression/ activity are needed to determine whether TRPC6 restricts or reverses progression of a SASP in IVD cells and mitigates the loss of regenerative capacity. This could possibly offer a means to treat IVD degeneration. So far, TRPC6 modulation has been investigated for focal segmental glomerulosclerosis [50], pulmonary hypertension [51] and ischaemia reperfusion-induced lung oedema [52]. TRP channel modulation could be achieved by gene editing, using CRIPSR/ Cas9 [37, 53, 54]. However, these approaches are still in an early experimental phase.

\section{Conclusions}

In conclusion, we show that human IVD cells subjected to RPM-simulated microgravity or to TRPC channel inhibition display reduced proliferation, retarded cell cycle progression and increased cell senescence. Furthermore, simulated microgravity reduces TRPC6 gene expression. The TRPC6 ion channel may hence be involved in mechanotransduction and in the regulation of cell proliferation and senescence in the IVD. These findings are in agreement with other studies where simulated microgravity induced signs of degeneration in whole mouse IVDs [17] and reduced proliferation in mouse myoblasts by inducing cell cycle arrest [28]. The fact that the effects caused by simulated microgravity (reduced proliferation, retarded cell cycle progression and increased senescence) were recapitulated by TRPC channel inhibition and were accompanied by downregulation of TRPC6 expression suggests that TRPC6 may potentially play a role in the underlying mechanisms. In fact, TRPC6 has also been associated with cell senescence in lung fibroblasts [30], a contributor to pulmonary hypertension [55], consequentially motivating first studies on the therapeutic potential of TRPC6 modulation [55]. This study thus reveals TRPC6 as a potential target for further studies aiming to investigate IVD degeneration.

Acknowledgements Open access funding provided by Paracelsus Medical University. The authors are thankful to Dr. Ermioni Touli (Hirslanden Klinik St. Anna, Switzerland) for support in biopsy collection.

Funding This study was funded by the Swiss National Science Foundation (SNF PP00P2_163678/1) and the Spine Society of Europe (Eurospine 2016_4).

\section{Compliance with ethical standards}

Conflict of interest All authors declare that they have no conflict of interest.

Ethical approval All procedures performed in studies involving human participants were in accordance with the ethical standards of the institutional and/or national research committee and with the 1964 Helsinki Declaration and its later amendments or comparable ethical standards.

Informed consent Informed consent was obtained from all individual participants included in the study. 
Open Access This article is distributed under the terms of the Creative Commons Attribution 4.0 International License (http://creativeco mmons.org/licenses/by/4.0/), which permits unrestricted use, distribution, and reproduction in any medium, provided you give appropriate credit to the original author(s) and the source, provide a link to the Creative Commons license, and indicate if changes were made.

\section{References}

1. Boos N, Weissbach S, Rohrbach H, Weiler C, Spratt KF, Nerlich AG (2002) Classification of age-related changes in lumbar intervertebral discs: 2002 Volvo Award in basic science. Spine 27:2631-2644. https://doi.org/10.1097/01.BRS.0000035304 $.27153 .5 \mathrm{~B}$

2. Adams MA, Roughley PJ (2006) What is intervertebral disc degeneration, and what causes it? Spine 31:2151-2161. https:// doi.org/10.1097/01.brs.0000231761.73859.2c

3. Chan D, Song Y, Sham P, Cheung KMC (2006) Genetics of disc degeneration. Eur Spine J 15:317-325. https://doi.org/10.1007/ s00586-006-0171-3

4. Wilke HJ, Neef P, Caimi M, Hoogland T, Claes LE (1999) New in vivo measurements of pressures in the intervertebral disc in daily life. Spine 24:755-762

5. Chan SC, Walser J, Kappeli P, Shamsollahi MJ, Ferguson SJ, Gantenbein-Ritter B (2013) Region specific response of intervertebral disc cells to complex dynamic loading: an organ culture study using a dynamic torsion-compression bioreactor. PLoS ONE 8:e72489. https://doi.org/10.1371/journal.pone.0072489

6. Chan SC, Ferguson SJ, Gantenbein-Ritter B (2011) The effects of dynamic loading on the intervertebral disc. Eur Spine J 20:17961812. https://doi.org/10.1007/s00586-011-1827-1

7. Belavy DL, Bansmann PM, Bohme G, Frings-Meuthen P, Heer M, Rittweger J, Zange J (1985) Felsenberg D (2011) Changes in intervertebral disc morphology persist $5 \mathrm{mo}$ after 21 -day bed rest. J Appl Physiol 111:1304-1314. https://doi.org/10.1152/japplphysi ol.00695.2011

8. Belavy DL, Armbrecht G, Felsenberg D (2012) Incomplete recovery of lumbar intervertebral discs 2 years after 60-day bed rest. Spine 37:1245-1251. https://doi.org/10.1097/BRS.0b013e3182 $354 \mathrm{~d} 84$

9. Wing PC, Tsang IK, Susak L, Gagnon F, Gagnon R, Potts JE (1991) Back pain and spinal changes in microgravity. Orthop Clin N Am 22:255-262

10. Kerstman EL, Scheuring RA, Barnes MG, DeKorse TB, Saile LG (2012) Space adaptation back pain: a retrospective study. Aviat Space Environ Med 83:2-7

11. Sayson JV, Hargens AR (2008) Pathophysiology of low back pain during exposure to microgravity. Aviat Space Environ Med 79:365-373. https://doi.org/10.3357/Asem.1994.2008

12. Johnston SL, Campbell MR, Scheuring R, Feiveson AH (2010) Risk of herniated nucleus pulposus among U.S. astronauts. Aviat Space Environ Med 81:566-574

13. Laws CJ, Berg-Johansen B, Hargens AR, Lotz JC (2016) The effect of simulated microgravity on lumbar spine biomechanics: an in vitro study. Eur Spine J 25:2889-2897. https://doi. org/10.1007/s00586-015-4221-6

14. Sinha RK, Shah SA, Hume EL, Tuan RS (2002) The effect of a 5-day space flight on the immature rat spine. Spine J 2:239-243

15. Bailey JF, Hargens AR, Cheng KK, Lotz JC (2014) Effect of microgravity on the biomechanical properties of lumbar and caudal intervertebral discs in mice. J Biomech 47:2983-2988. https ://doi.org/10.1016/j.jbiomech.2014.07.005

16. Wuest SL, Richard S, Kopp S, Grimm D, Egli M (2015) Simulated microgravity: critical review on the use of random positioning machines for mammalian cell culture. Biomed Res Int 2015:971474. https://doi.org/10.1155/2015/971474

17. Jin L, Feng G, Reames DL, Shimer AL, Shen FH, Li X (2013) The effects of simulated microgravity on intervertebral disc degeneration. The Spine J 13:235-242. https://doi.org/10.1016/j.spine e.2012.01.022

18. Stannard JT, Edamura K, Stoker AM, O'Connell GD, Kuroki K, Hung CT, Choma TJ, Cook JL (2016) Development of a whole organ culture model for intervertebral disc disease. J Orthop Transl 5:1-8. https://doi.org/10.1016/j.jot.2015.08.002

19. Kim KW, Chung HN, Ha KY, Lee JS, Kim YY (2009) Senescence mechanisms of nucleus pulposus chondrocytes in human intervertebral discs. Spine J 9:658-666. https://doi. org/10.1016/j.spinee.2009.04.018

20. Roberts S, Evans EH, Kletsas D, Jaffray DC, Eisenstein SM (2006) Senescence in human intervertebral discs. Eur Spine J 15(Suppl 3):S312-S316. https://doi.org/10.1007/s0058 6-006-0126-8

21. Grant MP, Epure LM, Bokhari R, Roughley P, Antoniou J, Mwale F (2016) Human cartilaginous endplate degeneration is induced by calcium and the extracellular calcium-sensing receptor in the intervertebral disc. Eur Cells Mater 32:137-151

22. Rakan B, AlGarni N, Salem O, Epure L, Habis AA, Antoniou J, Mwale F, Grant M (2015) Free calcium induces degenerative changes in the intervertebral disc through the calcium sensing receptor. Can J Neurol Sci 42:S50-S50. https://doi.org/10.1017/ cjn. 2015.226

23. Worley PF, Zeng W, Huang GN, Yuan JP, Kim JY, Lee MG, Muallem S (2007) TRPC channels as STIM1-regulated store-operated channels. Cell Calcium 42:205-211. https://doi.org/10.1016/j. ceca.2007.03.004

24. Walter BA, Purmessur D, Moon A, Occhiogrosso J, Laudier DM, Hecht AC, Iatridis JC (2016) Reduced tissue osmolarity increases TRPV4 expression and pro-inflammatory cytokines in intervertebral disc cells. Eur Cells Mater 32:123-136

25. Sadowska A, Touli E, Hitzl W, Greutert H, Ferguson SJ, WuertzKozak K, Hausmann ON (2018) Inflammaging in cervical and lumbar degenerated intervertebral discs: analysis of proinflammatory cytokine and TRP channel expression. Eur Spine J 27:564577. https://doi.org/10.1007/s00586-017-5360-8

26. Krupkova O, Zvick J, Wuertz-Kozak K (2017) The Role of Transient Receptor Potential Channels in Joint Diseases. Eur Cells Mater 34:180-201. https://doi.org/10.22203/eCM.v034a12

27. Ichikawa J, Inoue R (2014) TRPC6 regulates cell cycle progression by modulating membrane potential in bone marrow stromal cells. Br J Pharmacol 171:5280-5294. https://doi.org/10.1111/ bph. 12840

28. Benavides Damm T, Richard S, Tanner S, Wyss F, Egli M, Franco-Obregon A (2013) Calcium-dependent deceleration of the cell cycle in muscle cells by simulated microgravity. FASEB J Off Publ Fed Am Soc Exp Biol 27:2045-2054. https://doi. org/10.1096/fj.12-218693

29. Numata T, Kiyonaka S, Kato K, Takahashi N, Mori Y (2011) Activation of TRP channels in mammalian systems. In: Zhu MX (ed) TRP channels. Boca Raton (FL)

30. Chandrasekaran A, Zhang X, Lee MY, Shapiro R, Trebak M, Melendez JA (2017) 62- $\mathrm{H}_{2} \mathrm{O}_{2}$ and mTOR control the senescenceassociated secretory phenotype by coordinating $\mathrm{Ca}^{2+}$ transients through TRPC6 expression and activation. Free Radic Bio Med 112:55-56. https://doi.org/10.1016/j.freeradbiomed.2017.10.075

31. Crocetti S, Beyer C, Unternahrer S, Benavides Damm T, SchadeKampmann G, Hebeisen M, Di Berardino M, Frohlich J, FrancoObregon A (2014) Impedance flow cytometry gauges proliferative capacity by detecting TRPC1 expression. Cytom Part A J Int Soc Anal Cytol. https://doi.org/10.1002/cyto.a.22461 
32. Krupkova O, Handa J, Hlavna M, Klasen J, Ospelt C, Ferguson SJ, Wuertz-Kozak K (2016) The natural polyphenol epigallocatechin gallate protects intervertebral disc cells from oxidative stress. Oxid Med Cell Longev 2016:7031397. https://doi. org/10.1155/2016/7031397

33. Wuest SL, Richard S, Walther I, Furrer R, Anderegg R, Sekler J, Egli M (2014) A novel microgravity simulator applicable for three-dimensional cell culturing. Microgravity Sci Technol 26:7788. https://doi.org/10.1007/s12217-014-9364-2

34. Song M, Chen D, Yu SP (2014) The TRPC channel blocker SKF 96365 inhibits glioblastoma cell growth by enhancing reverse mode of the $\mathrm{Na}+/ \mathrm{Ca} 2+$ exchanger and increasing intracellular $\mathrm{Ca}^{2+}$. Br J Pharmacol 171:3432-3447. https://doi.org/10.1111/ bph.12691

35. Debacq-Chainiaux F, Erusalimsky JD, Campisi J, Toussaint O (2009) Protocols to detect senescence-associated beta-galactosidase (SA-beta gal) activity, a biomarker of senescent cells in culture and in vivo. Nat Protoc 4:1798-1806. https://doi.org/10.1038/ nprot.2009.191

36. Quero L, Klawitter M, Schmaus A, Rothley M, Sleeman J, Tiaden AN, Klasen J, Boos N, Hottiger MO, Wuertz K, Richards PJ (2013) Hyaluronic acid fragments enhance the inflammatory and catabolic response in human intervertebral disc cells through modulation of toll-like receptor 2 signalling pathways. Arthritis Res Ther 15:R94. https://doi.org/10.1186/ar4274

37. Krupkova O, Cambria E, Besse L, Besse A, Bowles R, WuertzKozak K (2018) The potential of CRISPR/Cas9 genome editing for the study and treatment of intervertebral disc pathologies. JOR SPINE 1:e1003. https://doi.org/10.1002/jsp2.1003

38. Wong VW, Longaker MT, Gurtner GC (2012) Soft tissue mechanotransduction in wound healing and fibrosis. Semin Cell Dev Biol 23:981-986. https://doi.org/10.1016/j.semcdb.2012.09.010

39. Crawford-Young SJ (2006) Effects of microgravity on cell cytoskeleton and embryogenesis. Int J Dev Biol 50:183-191. https ://doi.org/10.1387/ijdb.052077sc

40. Wuest SL, Stern P, Casartelli E, Egli M (2017) Fluid dynamics appearing during simulated microgravity using random positioning machines. PLoS ONE 12:e0170826. https://doi.org/10.1371/ journal.pone. 0170826

41. Cheng H, Curtis AE, Fellingham C, Hancox JC (2016) Multiple ion channel block by the cation channel inhibitor SKF-96365 in myocytes from the rabbit atrioventricular node. Physiol Rep 4:e12819. https://doi.org/10.14814/phy2.12819

42. Zhao H, Simasko SM (2010) Role of transient receptor potential channels in cholecystokinin-induced activation of cultured vagal afferent neurons. Endocrinology 151:5237-5246. https:// doi.org/10.1210/en.2010-0504

43. Vo NV, Hartman RA, Patil PR, Risbud MV, Kletsas D, Iatridis JC, Hoyland JA, Le Maitre CL, Sowa GA, Kang JD (2016) Molecular mechanisms of biological aging in intervertebral discs. J Orthop Res Off Publ Orthop Res Soc. https://doi.org/10.1002/jor.23195

44. Feng C, Liu H, Yang M, Zhang Y, Huang B, Zhou Y (2016) Disc cell senescence in intervertebral disc degeneration: causes and molecular pathways. Cell Cycle 15:1674-1684. https://doi. org/10.1080/15384101.2016.1152433

45. Wang F, Cai F, Shi R, Wang XH, Wu XT (2016) Aging and age related stresses: a senescence mechanism of intervertebral disc degeneration. Osteoarthr Cartil 24:398-408. https://doi. org/10.1016/j.joca.2015.09.019

46. Molinos M, Almeida CR, Caldeira J, Cunha C, Gonçalves RM, Barbosa MA (2015) Inflammation in intervertebral disc degeneration and regeneration. J R Soc Interface 12:20141191. https://doi. org/10.1098/rsif.2014.1191

47. Li Z, Guo G, Wang H, Si X, Zhou G, Xiong Y, Li S, Dai R, Yang C (2017) TRPC5 channel modulates endothelial cells senescence. Eur J Pharmacol 802:27-35. https://doi.org/10.1016/j.ejpha r.2017.02.037

48. Yee NS, Zhou W, Lee M, Yee RK (2012) Targeted silencing of TRPM7 ion channel induces replicative senescence and produces enhanced cytotoxicity with gemcitabine in pancreatic adenocarcinoma. Cancer Lett 318:99-105. https://doi.org/10.1016/j.canle t.2011.12.007

49. Yee NS, Brown RD, Lee MS, Zhou W, Jensen C, Gerke H, Yee RK (2012) TRPM8 ion channel is aberrantly expressed and required for preventing replicative senescence in pancreatic adenocarcinoma: potential role of TRPM8 as a biomarker and target. Cancer Biol Ther 13:592-599. https://doi.org/10.4161/cbt.20079

50. Winn MP, Conlon PJ, Lynn KL, Farrington MK, Creazzo T, Hawkins AF, Daskalakis N, Kwan SY, Ebersviller S, Burchette JL, Pericak-Vance MA, Howel DN, Vance JM, Rosenberg PB (2005) A mutation in the TRPC6 cation channel causes familial focal segmental glomerulosclerosis. Science 308:1801-1804. https:// doi.org/10.1126/science.1106215

51. Pousada G, Baloira A, Valverde D (2015) Molecular and clinical analysis of TRPC6 and AGTR1 genes in patients with pulmonary arterial hypertension. Orphanet J Rare Dis. https://doi. org/10.1186/s13023-014-0216-3

52. Weissmann N, Sydykov A, Kalwa H, Storch U, Fuchs B, Schnitzler MMY, Brandes RP, Grimminger F, Meissner M, Freichel M, Offermanns S, Veit F, Pak O, Krause KH, Schermuly RT, Brewer AC, Schmidt HHHW, Seeger W, Shah AM, Gudermann T, Ghofrani HA, Dietrich A (2012) Activation of TRPC6 channels is essential for lung ischaemia-reperfusion induced oedema in mice. Nat Commun. https://doi.org/10.1038/ncomms1660

53. Naldini L (2015) Gene therapy returns to centre stage. Nature 526:351-360. https://doi.org/10.1038/nature15818

54. Doudna JA, Charpentier E (2014) Genome editing. The new frontier of genome engineering with CRISPR-Cas9. Science 346:1258096. https://doi.org/10.1126/science.1258096

55. Noureddine H, Gary-Bobo G, Alifano M, Marcos E, Saker M, Vienney N, Amsellem V, Maitre B, Chaouat A, Chouaid C, Dubois-Rande JL, Damotte D, Adnot S (2011) Pulmonary artery smooth muscle cell senescence is a pathogenic mechanism for pulmonary hypertension in chronic lung disease. Circ Res 109:543553. https://doi.org/10.1161/CIRCRESAHA.111.241299

\section{Affiliations}

\section{Alfredo Franco-Obregón ${ }^{1,2}$ - Elena Cambria ${ }^{3} \cdot$ Helen Greutert $^{3} \cdot$ Timon Wernas $^{4} \cdot$ Wolfgang Hitzl $^{5,6} \cdot$ Marcel Egli $^{4}$. Miho Sekiguchi $^{7} \cdot$ Norbert Boos $^{8}$. Oliver Hausmann ${ }^{9} \cdot$ Stephen J. Ferguson $^{3} \cdot$ Hiroshi Kobayashi $^{3,7}$. Karin Wuertz-Kozak ${ }^{3,10,11,12}$}

Karin Wuertz-Kozak

kwuertz@ethz.ch
1 Department of Surgery, Yong Loo Lin School of Medicine, National University of Singapore, Singapore, Singapore 
2 Biolonic Currents Electromagnetic Pulsing Systems Laboratory, BICEPS, National University of Singapore, Singapore, Singapore

3 Institute for Biomechanics, D-HEST, ETH Zurich, Hönggerbergring 64, 8093 Zurich, Switzerland

4 School of Engineering and Architecture, Lucerne University of Applied Sciences and Arts, Lucerne, Switzerland

5 Research Office (Biostatistics), Paracelsus Private Medical University, Salzburg, Austria

6 Department of Ophthalmology and Optometry, Paracelsus Medical University Salzburg, Salzburg, Austria

7 Department of Orthopaedic Surgery, School of Medicine, Fukushima Medical University, Fukushima, Japan
9

Neuro- and Spine Center, Hirslanden Klinik St. Anna, Lucerne, Switzerland

10 Spine Center, Schön Klinik München Harlaching, 81547 Munich, Germany

11 Academic Teaching Hospital and Spine Research Institute, Paracelsus Private Medical University, Salzburg, Austria

12 Department of Health Science, University of Potsdam, Potsdam, Germany 